Research Article

\title{
Comparative study of case based learning with traditional teaching method in pharmacology for second year MBBS students
}

\author{
Srinivasa Kenchaiah ${ }^{1}$, Purushotham Krishna ${ }^{2} *$
}

${ }^{1}$ Department of Pharmacology, Chamarajanagar Institute of Medical Sciences, Chamarajanagar, Karnataka state, India

${ }^{2}$ Department of Pharmacology, Sri Siddhartha Medical College, Tumakuru, Karnataka, India

Received: 30 June 2016

Accepted: 04 July 2016

*Correspondence to:

Dr. Purushotham K.,

Email: pursotham2016

@ rediffmail.com

Copyright: (C) the author(s), publisher and licensee Medip Academy. This is an openaccess article distributed under the terms of the Creative Commons Attribution NonCommercial License, which permits unrestricted noncommercial use, distribution, and reproduction in any medium, provided the original work is properly cited.

\begin{abstract}
Background: Case based learning (CBL), a well-known teaching- learning method, implemented by many especially in medical teaching is very useful. It helps learner to identify what they already know and to restructure, elaborate their knowledge and provide bridge between existing and new information. So this study was conducted to compare case based learning (CBL) over traditional teaching method (TTM) in pharmacology for second year MBBS students.

Methods: CBL was initiated for the entire batch of 5th term students $(n=76)$. Three Sessions each of one hour using TTM and CBL were taken on two important topics, myocardial infarction and diabetes mellitus. Post-test for each teaching learning method was obtained and analyzed with paired $t$ test. Feedback in form of questionnaire was taken.

Results: We found that CBL is more effective than the TTM $(p<0.001)$.

Conclusions: Case based learning motivated students for fact finding, reasoning, and self-learning.
\end{abstract}

Keywords: CBL, TTM, Pharmacology

\section{INTRODUCTION}

The quality of medical education depends upon various factors like curriculum, college administration, infrastructure, patient exposure, faculty expertise in the subject and their knowledge, exposure and training in teaching-learning methodology. Moreover medical education in the past decade is witnessing a paradigm shift and is now becoming student centric from teachercentred mode. ${ }^{1}$
Therefore, student opinion and preferences matter the most before introduction of any additions, deletions or modifications in the way the course is conducted. At the same time students differs in age, place, ethnicity, level of preparedness, learning styles and preferences etc. ${ }^{2}$ Therefore it becomes a responsibility of any medical teacher to meet the individual educational need of the students regarding the knowledge, attitude, and the skill.

One of the most important ways to strengthen the medical education at content delivery level is to assess student perception about teaching- learning methodology. 
Numerous teaching-learning methods are practiced throughout MBBS course, to increase involvement, participation and interest of students, so that learning is facilitated and it appeal to students with different learning styles. The challenges of medical education in India are similar to other developing nations. Further, the curriculum is still taught discipline based, teachers lack skills in teaching-learning methods and student assessment. Thus, students lack opportunities for active and self-directed learning.

Case based learning (CBL), a very well-known teachinglearning method, adopted by many especially in medical teaching is very useful. It helps learner to identify what they already know and to restructure, elaborate their knowledge and provide bridge between existing and new information. Moreover CBL is student centered, taken in small groups where teacher acts as facilitator or guide. Problems are the vehicles for development of problem solving skills. New information is acquired through selfdirected learning. ${ }^{3}$ Also group discussion which is the part of CBL if effectively practiced develops a range of soft skills such as self-expression, listening, collaboration and problem solving. ${ }^{4}$ Learner can be given some challenging task, which they could solve independently and work with teachers and others. As they develop the abilities required, they shall receive less assistance and work more independently. Learning should be closely related to the understanding and solution of real world problem. ${ }^{5}$ It has been reported that medical graduates in India generally possesses reasonably sound knowledge of medical science but they are often found deficient in the performance of clinical skills and problem solving, which form the core of clinical competence. ${ }^{6} \mathrm{CBL}$ is one method where students are motivated to learn on their own so as to inculcate the habit of self-learning and integrating knowledge from different subjects to solve problems. It is a small-group method in which both students and faculty members contribute to discussion, learning issues are pre identified, and preparatory readings are assigned while student discussion and guided inquiry around clinical problems is promoted. ${ }^{7}$

The challenges in front of students of pharmacology are increasing day by day. The subject of pharmacology is introduced to the II MBBS students, which also involves clinical exposure for them. In CBL, a real world scenario with the supporting data and documents is given with open ended questions and the case content is closely aligned with the overall instructional goals and objectives. The learner is asked to read, identify, establish, discuss, and reflect on these goals and objectives. Regarding CBL, Wilkerson and Gijselares told that the teacher is facilitator rather than disseminator, observer rather than actor. They coach from the side lines providing constructive feedback and challenging students to excel. ${ }^{8}$ Many times, medical teaching gets restricted to didactic lectures, seminars, practical and this is most of the time teacher centered. As per Jena Vellas outlook "Adult learners have shown that they are willing, eager to learn in safe learning environment. Allowing small groups to find their voices enhance the power of safety. Trust in the sequence of activities builds safety where CBL is used". . CBL can be defined as a process in which by discussing a clinical case related to the topic taught, students evaluated their own understanding of the concept using a high order of cognition. This process encourages active learning and produces a more productive outcome. ${ }^{11-12}$ Undergraduate medical students at our institute in their feedback of pharmacology sessions have commented on the difficulty in applying the knowledge learnt during lecture classes in actual clinical postings. Hence we perceived the need for initiating $\mathrm{CBL}$ for large group teaching. So this project aimed to motivate knowledge acquisition by case centered learning.

\section{Objectives}

- To initiate CBL and evaluate its effectiveness over traditional teaching learning methods.

- To develop the soft skills such as self-expression, listening, collaboration and problem solving.

- To develop and gather perception of students regarding $\mathrm{CBL}$.

\section{METHODS}

This is an observational study conducted in KMCT Medical College, Kozhikode from September 2012 to April 2013. This research study was conducted on all 76 students of II MBBS after seeking permission from institutional ethical committee. Understandable idea of the research project was given to all the students and consent was taken from students who were willing to participate in this project. Ten ideal case scenarios on the topic of myocardial infraction and diabetes mellitus were prepared, and pre validated by the faculty of pharmacology and medical education department. Specific learning objects (SLO) were decided. Case scenarios with background of a patient, clinical situation, manifestation of adverse drug reactions (ADR photographs), drug interactions, contraindications and rational use of drug therapy were used. Cases were displayed during the session and students were given 8 minutes time to read, discuss and analyze with their neighbours. Later the questions were projected and students were given an opportunity to respond. Faculty only facilitated the learning process, discussed relevant points and summarized towards each case scenario.

\section{First intervention}

Three sessions each of one hour using TTM were taken on the topic of myocardial infraction and diabetes mellitus. Pre and post-test was taken on the traditionally taught topic, consisted of short answer questions (SAQ) of 20 marks within the time period of 30 minutes. 


\section{Second intervention}

CBL was introduced and total three sessions were conducted. During $1^{\text {st }}$ session, cases studies on myocardial infarction and diabetes mellitus were introduced to the students and relevant study material references were given. $2^{\text {nd }}$ session was given to the students for reading to find the learning trigger, establish connection, discuss, explore, compose and finally reflect. In the groups there was one leader, one time keeper, one scribe, and teacher as facilitator. In $3^{\text {rd }}$ session there was discussion, briefing by faculty, followed by post-test. Feedback by using 5 point Likert scale was obtained from the students in form of pre validated questionnaire which consisted of both close ended as well as open ended questions. Unpaired t-test was applied for comparison between the scores obtained in post-test of both teaching learning methods.

\section{RESULTS}

76 students participated in this study and gave their feedback for both the teaching methods (Table 1 and Figure 1).
Table 1: Mean of marks obtained after TTM and CBL.

\begin{tabular}{|c|c|c|c|c|}
\hline TL method & Mean & SD & SE & p value \\
\hline TTM & 12.2 & 1.81 & 0.31 & \multirow{2}{*}{$\begin{array}{l}\mathrm{P}<0.001 \\
\mathrm{t}=4.184, \mathrm{df}=21\end{array}$} \\
\hline CBL & 14.9 & 2.10 & 0.42 & \\
\hline
\end{tabular}

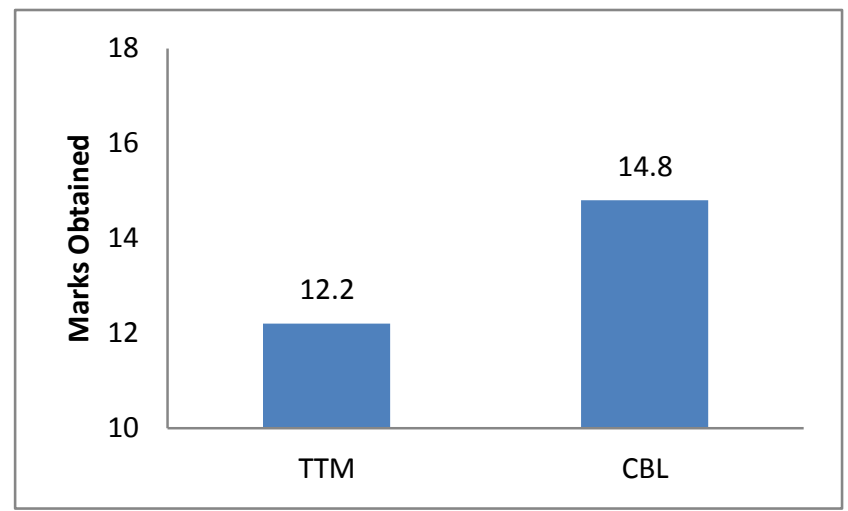

Figure 1: Mean of marks obtained after TTM and CBL.

Table 2: Analysis of percentage of student's feedback after TTM.

\begin{tabular}{|c|c|c|c|c|c|c|}
\hline \multicolumn{7}{|c|}{ Feedback analysis $(n=76)$} \\
\hline Sr. No. & Questions & Strongly disagree & Disagree & Neutral & Agree & Strongly agree \\
\hline Q.1 & Method is interesting & $40(52.26 \%)$ & $25(32.33 \%)$ & $7(9.33 \%)$ & $2(2.6 \%)$ & $2(2.6 \%)$ \\
\hline Q.2 & $\begin{array}{l}\text { Motivated to read more } \\
\text { and enhanced self-learning }\end{array}$ & $46(60.5 \%)$ & $20(26.31 \%)$ & $7(9.33 \%)$ & $1(1.31 \%)$ & $2(2.6 \%)$ \\
\hline Q.3 & Better understanding & $37(46.68 \%)$ & $17(22.36 \%)$ & $19(25 \%)$ & $3(3.9 \%)$ & 0 \\
\hline Q.4 & $\begin{array}{l}\text { Motivated critical thinking } \\
\text { and analytical skill }\end{array}$ & $47(61.9 \%)$ & $19(25 \%)$ & $6(7.8 \%)$ & $2(2.6 \%)$ & $2(2.6 \%)$ \\
\hline Q.5 & $\begin{array}{l}\text { Helped in memorizing the } \\
\text { fact easily }\end{array}$ & $44(57.8 \%)$ & $15(19.73 \%)$ & $\begin{array}{l}15 \\
(19.73 \%)\end{array}$ & $12(15.78 \%)$ & 0 \\
\hline Q.6 & $\begin{array}{l}\text { Helped fact finding and } \\
\text { correlating principles of } \\
\text { diagnosis and management } \\
\text { of disease }\end{array}$ & $50(65.7 \%)$ & $8(10.5 \%)$ & $9(11.7 \%)$ & $1(1.31 \%)$ & $1(1.31 \%)$ \\
\hline Q.7 & $\begin{array}{l}\text { Increased group interaction } \\
\text { and made clinical learning } \\
\text { easier and enjoyable }\end{array}$ & $35(41.67 \%)$ & $10(13.4 \%)$ & $13(17.5 \%)$ & $1(1.31 \%)$ & 0 \\
\hline Q.8 & $\begin{array}{l}\text { Increased sensitivity } \\
\text { towards patients problem }\end{array}$ & $47(61.8 \%)$ & $9(11.84 \%)$ & $9(11.84 \%)$ & $2(2.6 \%)$ & $1(1.31 \%)$ \\
\hline Q.9 & $\begin{array}{l}\text { Gives confidence in bed } \\
\text { side case presentation }\end{array}$ & $50(65.7 \%)$ & $15(19.73 \%)$ & $7(9.33 \%)$ & $5(8.33 \%)$ & $1(1.31 \%)$ \\
\hline Q.10 & $\begin{array}{l}\text { To be continued and } \\
\text { implemental }\end{array}$ & $59(77.6 \%)$ & $8(10.5 \%)$ & $5(6.5 \%)$ & $4(4.7 \%)$ & 0 \\
\hline
\end{tabular}

There was significant difference in the knowledge gain of the student as their performance in post-test of CBL was better when compared with TTM post test score $(\mathrm{p}<0.001)$. Students perceived CBL as a better teaching learning method than Traditional TL method. $92.33 \%$ of students strongly agreed that CBL method was interesting and $52.6 \%$ students found the TTM to be non-interesting.
92.1\% students strongly agreed that CBL motivated them to read more, enhance self-learning, and hence better understanding was achieved. While $60.5 \%$ of students found that TTM didn't motivate them to read more and $85.17 \%$ strongly agreed that CBL helped them to memorize the facts easily and also increased their group interaction and made clinical learning easier and 
enjoyable. While $83.33 \%$ students said that TTM doesn't increase any group interaction, neither learn through this method is easier or enjoyable. $83.5 \%$ students strongly agreed that CBL method increased their sensitivity towards patient's problem. $71.4 \%$ strongly agreed that this method of CBL should be continued and to be regularly implemented, while $77.6 \%$ of students suggested to discontinue TTM (Table $2 \& 3$ ).

Table 3: Analysis of percentage of student's feedback after CBL.

\begin{tabular}{|c|c|c|c|c|c|c|}
\hline \multicolumn{7}{|c|}{ Feedback analysis (n=76) } \\
\hline Sr. No & Questions & Strongly disagree & Disagree & Neutral & Agree & Strongly agree \\
\hline Q.1 & Method is interesting & 0 & 0 & 0 & $6(7.8 \%)$ & $70(92.1 \%)$ \\
\hline Q.2 & $\begin{array}{l}\text { Motivated to read more and } \\
\text { enhanced self-learning }\end{array}$ & 0 & 0 & 0 & $6(7.8 \%)$ & $70(92.1 \%)$ \\
\hline Q.3 & Better understanding & 0 & 0 & 0 & $6(7.8 \%)$ & $70(92.1 \%)$ \\
\hline Q.4 & $\begin{array}{l}\text { Motivated critical thinking and } \\
\text { analytical skill }\end{array}$ & 0 & 0 & 0 & $7(9.33 \%)$ & $69(90.3 \%)$ \\
\hline Q.5 & $\begin{array}{l}\text { Helped in memorizing the fact } \\
\text { easily }\end{array}$ & 0 & 0 & 0 & $\begin{array}{l}11 \\
(14.47 \%)\end{array}$ & $65(85.5 \%)$ \\
\hline Q.6 & $\begin{array}{l}\text { Helped fact finding and correlating } \\
\text { principles of diagnosis and } \\
\text { management of disease }\end{array}$ & 0 & 0 & $\begin{array}{l}2 \\
(2.66 \%)\end{array}$ & $9(11.7 \%)$ & $65(85.5 \%)$ \\
\hline Q.7 & $\begin{array}{l}\text { Increased group interaction and } \\
\text { made clinical learning easier and } \\
\text { enjoyable }\end{array}$ & 0 & 0 & 0 & $\begin{array}{l}10 \\
(13.15 \%)\end{array}$ & $66(87.4 \%)$ \\
\hline Q.8 & $\begin{array}{l}\text { Increased sensitivity towards } \\
\text { patients problem }\end{array}$ & 0 & 0 & $\begin{array}{l}3 \\
(3.94 \%)\end{array}$ & $9(11.7 \%)$ & $64(83.5 \%)$ \\
\hline Q.9 & Gives confidence in bed side & 0 & 0 & 0 & $9(11.7 \%)$ & $64(83.5 \%)$ \\
\hline Q.10 & To be continued and implemental & 0 & 0 & 0 & $5(6.55 \%)$ & $71(93.4 \%)$ \\
\hline
\end{tabular}

\section{DISCUSSION}

Correct diagnosis, ideal application of pharmacological treatment definitely gives a rewarding success in the student's career as well as ensures proper management of disease. For this purpose, the student should know the detailed patho-physiology of a disease with the various treatment options. The subject of pharmacology is introduced to the II year MBBS students, where students will also have clinical exposure. To get well versed with the patho-physiology and symptoms of the various diseases so as to make perfect diagnosis, it is necessary for the learners to study various cases. Subject of pharmacology is generally taught with help of didactic lectures, practical, and tutorials, as we know these methods are teacher centered and learners play a passive role. Hence considering the above facts and also to gather perception of students regarding $\mathrm{CBL}$ and to compare effectiveness in teaching learning methods we selected the topic of case based learning.

In CBL, a real world scenario with the supporting data and documents is given with open ended questions and the case content is closely aligned with the overall instructional goals and objectives. This certainly gives learner an opportunity to develop their own understanding and self-directed learning, combined with dialogue with their teachers and peers. We found that CBL was more interesting than traditional teaching method. Participants enjoyed as they were given a challenging task which they could solve independently and work on these with teachers and others. As per the feedback, adult learners were willing to learn in safe learning environment.

As the students are passive learners in traditional teaching method, whereas in CBL one has to actively participate in group activity by increasing the group interaction. Team work is a principle of adult learning as well as an effective practice 12. Group discussion also improves better understanding of the given topic. It will motivate them to read more. Students also agreed that CBL helped them to memorize the information easily and also increased their group interaction and made clinical learning easier and enjoyable. This method also increased their sensitivity towards solving patient's problem.

It was also observed that CBL not only enhances subject knowledge but also helped the students towards good diagnosis, ideal application of pharmacological intervention, good communications, listening skills, counselling, team work and also leadership skills.

\section{CONCLUSION}

CBL method was found to be more effective than traditional TTM in form of didactic lecture. And also 
CBL is better for integrating the knowledge gained in pharmacology to the bedside clinics. CBL for large group teaching can be implemented for other topics, to ensure effective learning.

This study was conducted on second year MBBS students of our institution. For better interpretation and results which could be applied at university, state or national level, we recommend a wide spread multi-centric study in medical colleges all over the country, having representation from all strata of students, faculty and policy makers.

Funding: No funding sources Conflict of interest: None declared

Ethical approval: The study was approved by the Institutional Ethics Committee

\section{REFERENCES}

1. Nanda B, Manjunatha S. Indian medical students' perspectives of problem-based learning experiences in undergraduate curriculum: one size does not fit all. J Educ Eval Health Prof. 2013;10:11.

2. Gade S, Chari S, Dasgupta S. Perception of the medical students of a private medical college on their future career. Indian J Appl Research. 2013;3(10):1-4.

3. Barrows HS. Bringing problem based learning in higher education: Theory and Practice. Problem based learning in Medicine and beyond: a brief overview, Francisco, Jossey-Bass Inc. Publishers;1996:5.
4. Jagues D. ABC of learning \& teaching in medicine. Teaching small groups, 2nd Edition. UK:Wiley Black Well Publications (BMJI books); 2010:23.

5. Kaufman DM. ABC of learning \& teaching in Medicine. Applying educational theory in practice, 2nd Edition, UK:Wiley Black Well Publications (BMJI books); 2010:5.

6. Verma K, D’Monte B, Adkoli BV, Nayar U. Inquirydriven strategies for innovation in medical education in India. New Delhi: AIIMS, 1992.

7. Srinivasan M, Wilkes M, Stevenson F, Nguye T, Slavin S. Comparing problem-based learning with case-based learning: Effects of a major curricular shift at two institutions. Acad Med. 2007;82:74-82.

8. Wilkerson L, Gijsealaers WH. Bringing problem based learning in higher education: Theory and Practice, Concluding Comments, San Francisco, Jossey-Bass Inc. Publishers;1996:101.

9. Vella J. Learning to listen, learning to teach. Safety, Revised Edition, San Francisco, Jossey-Bass Publishers;2002:71.

10. Lake DA. Student performance and perception of a lecture-based course compared with the same course utilizing group discussion. Phys Ther. 2001;81:896902.

11. Modell HI. Preparing students to participate in an active learning environment. Adv Physiol Educ. 1996;270:69-77.

12. Vella J. Learning to listen, learning to teach. Team work, revised edition, San Francisco, Jossey-Bass Publishers; 2002:191.

Cite this article as: Kenchaiah S, Krishna P. Comparative study of case based learning with traditional teaching method in pharmacology for second year MBBS students. Int J Basic Clin Pharmacol 2016;5:1210-4. 